\title{
Mujeres y ciudadanía: Orígenes de un derecho y un debate sobre la participación política de las mujeres en el Gobierno*
}

\author{
Álvaro Acevedo Tarazona', Cirly Uribe Ochoa² \\ Universidad Industrial de Santander (Colombia)
}

Recibido: enero 25 de 2015 - Revisado: febrero 17 de 2015 - Aceptado: mayo 20 de 2015

Referencia formato APA: Acevedo, A., \& Uribe, C. (2015). Mujeres y ciudadanía: Orígenes de un derecho y un debate sobre la participación política de las mujeres en el Gobierno. Revista Cientifica Guillermo de Ockham 13(1), 109-116.

\section{Resumen}

Este artículo reflexiona sobre los debates políticos llevados a cabo por pensadores como Rousseau, Sieyes, Diderot, Condorcet y Olympe de Gouges, entre otros, sobre la participación e inclusión política de la mujer en el marco de la Revolución Francesa, un contexto social e histórico importante por las implicaciones que tendría en el surgimiento del Estado liberal, a propósito del reconocimiento de la ciudadanía como el atributo que otorga el derecho a participar en los asuntos del Estado y del Gobierno. La ciudadanía se configuró como la doble capacidad de elegir a los gobernantes y asumir la vocería de la voluntad general para determinar el rumbo de una nación. Sin embargo, en su momento las mujeres fueron relegadas de esta posibilidad y se desconoció para ellas la máxima reivindicación que había motivado la Revolución Francesa: la igualdad.

Palabras clave: Ciudadanía, gobierno, participación política, discriminación, derechos de las mujeres

\section{Women and citizenship: Origins of a right and a debate on the political participation of women in government}

\section{Abstract}

This paper reflects on the political debates conducted by thinkers such as Rousseau, Sieyes, Diderot, Condorcet, Olympe de Gouges, among others, about political participation and inclusion of women in the context of the French Revolution; a very important social and historical context because of the implications it would have in the rise of the Liberal State concerning the recognition of citizenship as the attribute that gives the right to participate in State issues. Citizenship was configured as a dual ability to choose rulers and take on the voice of the general will to determine the direction of a nation; however, at the time, women were relegated of this possibility, not being able to know the maximum claim that had motivated the French Revolution: equality.

Keywords: Citizenship, government, political participation, discrimination, women's rights

\footnotetext{
* Este artículo se deriva del proyecto ¿Colombia indignada? Estudiantes y movilización por la educación superior (2011-2012), adscrito a la VIE-UIS. También forma parte de la investigación sobre participación política de la mujer en los cuerpos colegiados legislativos de Santander durante el Frente Nacional, en el marco de la investigación sobre educación y movimientos sociales en los años sesenta y setenta en Colombia.

1. Profesor de la Universidad Industrial de Santander. Doctor en Historia. Director del Grupo de Investigación Políticas, Sociabilidades y Representaciones Histórico-Educativas (Psorhe). E-Mail: tarazona20@gmail.com

2. Profesora de la Universidad Cooperativa de Colombia, sede Bucaramanga. Magíster en Historia de la Universidad Industrial de Santander. E-mail: yarima53@yahoo.com
} 


\section{Mulheres e cidadania: Origens de um direito e um debate sobre a participação política das mulheres no governo}

\section{Resumo}

Este artigo reflete sobre os debates políticos detidos pensadores como Rousseau, Sieyès, Diderot, Condorcet, Olympe de Gouges, entre outros, sobre a participação política e inclusão das mulheres no contexto da Revolução Frances; um muito importante por causa das implicaçóes que isso teria sobre o surgimento do Estado Liberal, sobre o reconhecimento da cidadania como o atributo que lhe dá o direito de participar nos assuntos de Estado e de governo social e contexto histórico. Cidadania é configurada como uma dupla capacidade de escolher os governantes e tomar a gritaria da vontade geral para determinar o curso de uma nação; no entanto, na época, as mulheres eram relegadas a esta possibilidade, desconhecido para eles exigir a indemnização máxima que havia motivado a Revolução Francesa: igualdade.

Palavras chave: Cidadania, governo, participação política, a discriminação, os direitos das mulhere

\section{Introducción}

Han transcurrido más de doscientos años desde los eventos que dieron origen a la Revolución Francesa y con ella al surgimiento de un nuevo orden político que transformaría las ideas sobre el Gobierno. Por siglos, este se consideró de origen divino y al pueblo como objeto de dominio y relegado de toda participación que no fuera la de pagar impuestos. Sin embargo, una pequeña parte de la sociedad conformada por el clero y la nobleza, gozó bajo los distintos regímenes de privilegios relacionados con el estatus y la fortuna.

Tal situación, aunada al surgimiento de una nueva clase social (la burguesía) y con ella el movimiento cultural de la Ilustración -amén de otros acontecimientos como la Revolución Industrial inglesa y la independencia de los Estados Unidos-, configuró nuevas aspiraciones políticas y sociales que reclamaban sociedades más igualitarias y libres; reivindicaciones que con grandes dificultades han sido asumidas desde aquel lejano 1789 hasta nuestros días por diversos grupos sociales marginados, para lograr su inclusión y el reconocimiento de su estatus en la sociedad. Entre estos grupos están las mujeres, quienes desde los orígenes de la Revolución Francesa y los distintos estamentos sociales existentes para ese entonces, protestaron por sus condiciones de pobreza, marginación y subvaloración social impuestas por el solo hecho de ser mujeres y exigieron su participación en igualdad de condiciones con los hombres en la construcción del nuevo orden político que se vislumbraba en las postrimerías del siglo XVIII y auguraba el final de la desigualdad social y política mediante el reconocimiento de ciudadanos sujetos de derechos.
En este contexto histórico, surgieron voces a favor y en contra de extenderles a las mujeres, el reconocimiento del derecho a la ciudadanía y con este a participar y ser consideradas sujetos políticos, cuyos intereses tuviesen no solo importancia sino también vocería y representatividad en el ámbito público. Voces femeninas y masculinas argumentaron desde la razón, la pasión y los prejuicios existentes sobre el ser, el hacer, el tener y el estar de las mujeres. Para unos, su mundo debía seguir siendo el hogar; para otros, este debía ampliarse hacia lo público, para que la tan pregonada igualdad fuese una realidad. De lo contrario, ¿̨ómo sostener su andamiaje discursivo y su materialidad cuando el $50 \%$ de la población vivía en condiciones de inferioridad y subvaloración social, económica, política y cultural?

Aunque luego de más de dos siglos las mujeres han conquistado la ciudadanía y logrado el reconocimiento de sus derechos, lo cual les ha permitido ocupar espacios importantes en la vida política, económica y social, aún se está lejos de la anhelada igualdad. ¿Qué prejuicios o razones -evidentes en los debates desarrollados en el contexto histórico de la Revolución Francesa y que sustentaron la exclusión femenina del mundo político- siguen sustentando la inequidad entre hombres y mujeres?

Este trabajo se suma a las investigaciones que un grupo variado de hombres y mujeres de distintas disciplinas vienen desarrollando a nivel internacional, nacional y local, sobre las relaciones de género en la política y la lucha de estas y otros grupos sociales para lograr su inclusión y la representación de sus intereses en los espacios de decisión política, con miras a establecer una sociedad más equitativa y democrática.

$110<$ Universidad de San Buenaventura, Cali - Colombia 


\section{Participación política: posturas a favor y en contra de la inclusión de las mujeres}

Con el advenimiento de las revoluciones políticas, económicas y sociales del siglo XVIII en las sociedades norteamericana, inglesa y francesa principalmente, surgió un nuevo orden político que amplió la participación política de quienes eran considerados ciudadanos -no súbditos-, cuyos ideales de igualdad y libertad han tardado más de 200 años en ampliar su reconocimiento al conjunto total de la nación, en un proceso que va del sufragio censitario y capacitario propuesto por el Abad de Sieyés al sufragio universal.

Las ideas desarrolladas por Voltaire, Rousseau, Montesquieu, Diderot, Adam Smith, John Stuart Mill, John Locke y Hobbes, entre otros, hicieron posible la configuración de este nuevo orden político conocido como Estado liberal o de derecho, cuyos inicios se sitúan en la Revolución Francesa. Abordar el análisis del ideario de estos pensadores, resulta fundamental para comprender cómo las representaciones mentales presentes en una sociedad determinan o influyen en procesos políticos, sociales o económicos y afectan los intereses de grupos humanos concretos al retrasar o dificultar la consecución de sus reivindicaciones con las cuales, de obtenerse, contribuirían al desarrollo propio y al de la sociedad que los contiene.

En este contexto surgen los debates alrededor de un triángulo conceptual que configura el andamiaje del nuevo orden político: participación, ciudadanía y representación, cuya base es el poder y lleva a una pregunta medular: ¿quiénes pueden participar en los asuntos del Estado y del Gobierno? Una pregunta pertinente, si se tiene en cuenta que en el Estado liberal los gobernantes son elegidos y su mandato tiene límites temporales y jurídicos. En el mismo orden, se crea e institucionaliza la división de poderes como fórmula expedita para evitar la tiranía, al dividir el poder del Estado en tres ramas que se regulan entre sí, en una de las cuales -la rama legislativa- debe haber representación del pueblo, que es el que elige.

Todos estos debates transcurren en el ámbito concreto del espacio público en el que discurren con fuerza la política y la economía de una sociedad. Ello implica que en esta atmósfera la participación es política, por cuanto entrańa para un sujeto ser considerado esencialmente ciudadano; es decir, sujeto libre, con derechos y deberes, con un estatus especial que lo inviste de poder para tomar decisiones en los asuntos del Estado y elegir y ser elegido como gobernante o legislador. Esta condición exige autonomía, vale decir, libertad; la cual, a su vez, exige capacidad de razonar, con lo cual no solo se conocen los asuntos del Estado, sino que también se dimensiona las consecuencias de los actos propios y de los demás y por lo tanto se adquiere la capacidad de establecer juicios éticos y morales que guían las actuaciones.

La libertad, como otro de los principios liberales, se afirma en la igualdad, según lo propone Sieyés: "No se es libre gracias a los privilegios, sino en virtud de los derechos del ciudadano que a todos pertenecen por igual" (Sieyes, 1789). Esta última condición, que hace referencia fundamentalmente a la independencia, segregó del espacio público a numerosos grupos humanos entre los que estaban las mujeres, quienes por cuenta de la división sexual del trabajo continuaron confinadas al espacio privado y bajo la tutoría de un hombre, ya fuese este padre, hermano, esposo o hijo. Al ser consideradas seres débiles e irracionales y por lo tanto incapaces de tomar decisiones por sí mismas, su participación en el espacio público no tendría garantía alguna de independencia. Además, su confinamiento al espacio privado era una forma de protegerlas y obtener lo mejor que ellas podían aportarles a la familia y a la sociedad: amor, ternura, comprensión, delicadeza, dulzura y belleza. Todo ello configuró lo que Choderlos de Laclos llamó la "utilidad social" de las mujeres, que las hacía esclavas y cuya liberación dependía de una revolución que ellas lideraran: "Aprended que no se sale de la esclavitud si no es por una gran revolución. ¿Es posible tal revolución? Solo vosotras lo podéis decir puesto que depende de vuestra valentía" (Choderlos de Laclos, 2010, p. 37).

La exclusión de las mujeres de la ciudadanía en este período histórico suscitó numerosos debates, puesto que tal decisión implicaba dejar por fuera de la toma de decisiones a la mitad de la población y cuestionaba la idea misma de igualdad, preconizada como uno de los principios de la filosofía liberal, el cual implicaba reconocer en el otro el atributo de dignidad que reclamaba para sí, como en su momento afirmara Diderot (1999): "La igualdad de los ciudadanos radica en que todos estén sometidos a las mismas leyes". Este sometimiento de los ciudadanos fue planteado también por Rousseau en el Contrato social cuando afirmó que al comprometerse todos los ciudadanos "bajo las mismas condiciones [...] deben gozar todos los mismos derechos". Sin embargo, este autor ilustrado, defensor irrestricto de la igualdad de los hombres, consideró como algo natural la desigualdad que vivían las mujeres. Por ello, Rousseau "no solo no impugna la desigualdad, sino que la defiende y legitima” (Caderón, 2004) al afirmar en varios de sus escritos -como el Segundo discurso y Emilio o De la educación- que el lugar de las mujeres, 
por naturaleza, era el hogar, y las exhortaba diciéndoles: "FFelices cuando vuestro casto poder, ejercido solamente en la unión conyugal, no se hace sentir más que para gloria del Estado y a favor del bienestar público!" (Rousseau, 2004).

A pesar de discursos como los de Rousseau y otros pensadores, para autores como Sieyés, Condorcet y John Stuart Mill, ${ }^{3}$ entre otros, el sexo no constituía un requisito para ser reconocido ciudadano. Para Sieyés, la condición de ciudadano tenía como prerrequisitos una capacidad intelectual obtenida por la ilustración y una independencia económica proporcionada por una renta con la cual se garantizase la satisfacción de necesidades existenciales y, por ende, la autonomía de la participación. Una persona que alcanzara esta condición no estaba sometida a tipo de servidumbre alguno.

El núcleo de las preocupaciones políticas y filosóficas de Sieyés en su teoría de la representación, no estuvo dirigido a la existencia de las desigualdades establecidas en el marco de un orden cultural (y ni siquiera económico), sino social. Dirigió sus cuestionamientos a la persistencia de un orden basado en los privilegios -a su vez fundados en el reconocimiento de linajes familiares- los cuales llamó y describió como:

Una clase de personas que, sin funciones ni utilidad alguna y por el solo hecho de su existencia, gozan de privilegios vinculados a su persona. Desde este punto de vista no hay sino una casta privilegiada: la nobleza. Esta constituye ciertamente un pueblo aparte, pero un pueblo falso que, no pudiendo en defecto de órganos útiles existir por sí mismo, se fija a una nación del mismo modo que esos tumores vegetales que viven de la savia de las plantas a las cuales parasitan y, finalmente, desecan (Sieyés, 1789, p. 7).

Para Sieyés, estos privilegios impedían la consolidación de la nación, que el autor entendía como una entidad colectiva asociada regida por una ley común que los representaba en una misma legislatura. De manera que la existencia de prerrogativas conducía a que este cuerpo social se encontrase apartado de los demás ciudadanos, es decir, se constituyese un imperium in imperio que desvanecía la esencia de una nación (Sieyés, 1789).

Sieyés asumió la cultura hegemónica de su época dando por hecho la existencia en la nación de grupos humanos en condición de servidumbre y a quienes excluía de ser considerados ciudadanos (Sieyés, 1789, p. 8). Sobre las mujeres, este pensador las referenciaba, en términos generales, como un grupo excluido per se de los espacios de representación al afirmar: "Por lo que a las mujeres respecta, estas -bien o mal es otro problema, en el que ahora no entraremos-, se ven alejadas por doquier de esta suerte de procuración" (Sieyés, 1789, p. 20). Con esta postura se hacía caso omiso de particularidades que permitiesen posibilitar la inclusión de las mujeres en la vida política. El foco de la argumentación de Sieyés pasaba por alto el detalle de que en aquel momento ya existía un grupo de mujeres que, aunque reducido, cumplía con los requisitos exigidos para pertenecer al grupo de personas con capacidad económica e intelectual para contribuir al establecimiento público. Sin más análisis sobre estas condiciones de exclusión en las que permanecían las mujeres, de manera tácita quedó establecido en la teoría de Sieyés que solo eran susceptibles de ser considerados ciudadanos activos un grupo reducido de varones que además de ilustrados, poseyeran bienes o rentas. Todos los demás -según este autor- podían disfrutar de unos derechos civiles que les otorgaba el reconocimiento de una ciudadanía pasiva.

Las afirmaciones de Sieyés revelan contradicciones cuando planteó que "La igualdad de los derechos políticos es un principio fundamental. Es sagrada, como la igualdad de los derechos civiles. De la desigualdad de los derechos políticos surgirían más bien los privilegios" (Noria, 1999, p. 99). No obstante, al enfatizar que la representación del tercer estado no era verdadera, concluía, por lo tanto, que sus derechos políticos eran nulos.

Otra interpretación a la que se podría llegar después de leer la obra de Sieyés es el carácter transitorio que dio a la situación de exclusión de estos grupos humanos, la cual podía ser superada a través del tiempo en cuanto se concretara el goce de los derechos civiles. Si bien la teoría de Sieyés sobre la representación dejaba rendijas a través de las cuales los grupos históricamente excluidos de la participación política -como las mujeres- pudieran llegar a acceder a la ciudadanía activa, otros autores como el Marqués de Condorcet (Puleo, 2011) (filósofo, matemático y político francés) esgrimieron argumentos de mayor radicalidad en favor del derecho de las mujeres a la ciudadanía.

Para este autor, las diferencias entre hombres y mujeres solo estaban referenciadas por la mayor fuerza física de los primeros y la coacción que se estableciese sobre el alma y el pensamiento de las segundas desde la misma infancia y su exclusión de la educación. Por tal razón consideraba que:

3. John Stuart Mill publicó ochenta años después de los acontecimientos de la Revolución Francesa, el texto La Esclavitud de la mujer (1869).

$112<$ Universidad de San Buenaventura, Cali - Colombia 
[...] las mujeres tienen los mismos derechos que los hombres; ellas tienen, pues, el derecho de obtener las mismas facilidades para adquirir los conocimientos, los únicos que pueden darles los medios de ejercer realmente estos derechos con una misma independencia e igual extensión (Puleo, 2011, p. 99).

De igual forma, replicaba en favor de los derechos de las mujeres al señalar que por la persistencia de hábitos, filósofos y legisladores se ocuparan "con mayor celo de establecer los derechos comunes de los individuos de la especie humana para hacer de ellos el fundamento único de las instituciones públicas". Estos filósofos y legisladores habían pasado por encima el principio de igualdad al excluir a las mujeres del derecho ciudadano que les pertenecía; no obstante, se preguntaban:

¿Hay acaso prueba más contundente del poder del hábito, incluso en los hombres ilustrados, que la de ver cómo se invoca el principio de la igualdad de los derechos a favor de trescientos o cuatrocientos hombres a los que un prejuicio absurdo había discriminado y olvidar ese mismo principio con respecto a doce millones de mujeres? (Puleo, 2011, p.101).

El marqués de Condorcet rebatió uno a uno los argumentos a los que se recurrió en su momento para no otorgarles la ciudadanía a las mujeres. Este consideraba que si "los derechos de los hombres se derivan únicamente de que son seres sensibles, susceptibles de adquirir ideas morales y de razonar con esas ideas" (Puleo, 2011, p.101) -cualidades que también tenían las mujeres-, la consecuencia era que también las mujeres tenían iguales derechos.

Otro de los argumentos de Condorcet para otorgarles la ciudadanía a las mujeres era que si se las consideraba seres incapaces de ejercer tales derechos de ciudadanía por estar expuestas a embarazos $\mathrm{u}$ otras situaciones propias de la mujer, por qué, entonces, no se privaba igualmente de estos derechos a otras personas como hombres con discapacidades físicas o enfermedades. Igual argumentación esgrimía en aspectos relacionados con la educación y la investigación, puesto que estas cualidades eran de pocos hombres, pero no de todos. Luego, existirían niveles de igualdad entre esos otros hombres y las mujeres. Terminaba afirmando cómo las diferencias entre los hombres y las mujeres estaban determinadas más por la educación y la vida social que por su misma naturaleza.

En razón de los argumentos del sufragio censitario, Condorcet propuso que este se extendiera a todas las cabezas de familia que fuesen propietarias, lo cual permitiría la inclusión de aquellas mujeres dueñas de feudos. Condorcet consideraba que los hombres no podían representar a las mujeres por tener intereses diferentes, aspecto que sustentaba en las normas y leyes en contra de las mujeres que eran opresivas y discriminatorias, las cuales habían sido establecidas por hombres.

En la misma obra -Esbozo de un cuadro histórico de los progresos del espiritu humano- Condorcet afirmaba que para el logro de la felicidad general era necesario

[...] destruir los prejuicios establecidos entre los sexos, una desigualdad de derechos funesta para el mismo que la favorece, [la cual] no tiene otro origen que el abuso de la fuerza y a partir de ahí se ha intentado, sin lograrlo, excusarla con sofismas (Puleo, 2011, p.108).

Ni siquiera aceptó los motivos de "utilidad pública" para diferenciar derechos. $\mathrm{Al}$ respecto, argumentó que estos no eran más que una excusa por parte de los tiranos, dado que, bajo el ropaje de la utilidad y del mercado en general se mantenían encadenados a los africanos, se nombraba censores de libros y se procedía a la tortura como mecanismo de instrucción.

Condorcet argumentaba que para reconocerle la ciudadanía al sexo femenino, solo se requeriría generar cambios en las costumbres a través de la educación y la destrucción de la tiranía, ejercida a través de leyes civiles, que mantenía a las mujeres alejadas de los asuntos públicos y atadas a su casa. Por ello, la injusticia no podía ser motivo para cometer otra injusticia (Puleo, 2011).

Como parte fundamental de estos debates, se conocieron la voz y los argumentos de mujeres que desde diferentes estamentos plantearon reivindicaciones para su inclusión, las cuales iban desde el mejoramiento de la educación que se les brindaba, pasaban por el derecho al divorcio y terminaban en el derecho al sufragio. Estos argumentos se expusieron en los llamados Cuadernos de quejas enviados a la reunión de los estados generales convocada por Luis XVI, en la que participaron representantes del clero, la nobleza y el tercer estado o pueblo llano.

A esa instancia las mujeres hicieron llegar sus quejas frente a la situación que vivían y las propuestas para superarla. Protestaron por la pobreza a la que eran sometidas al recibir salarios exiguos por su trabajo y ser despojadas de toda herencia para dársela al varón de los hermanos mayores o de la dote por el marido, aportada en el matrimonio; recibir una educación descuidada y defectuosa que solo les enseñaba a leer contenidos específicos como el Oficio de la misa en idioma francés y las Visperas en latín o les llenaban la cabeza con trivialidades, como si estuvieran destinadas a proporcionar únicamente los placeres del harén y verse sometidas a las obligaciones que les imponía el matrimonio las cuales las dejaban bajo el dominio absoluto de los 
hombres y en condiciones peores que las de los esclavos. Además de tener que contribuir con una dote -es decir, pagar para servir- no tenían su propio peculio y comida, como sí podían tenerlo los esclavos (Puleo, 2011).

Mujeres como Madeimoselle Jodin, remitieron a la Asamblea Constituyente un proyecto de legislación para las mujeres que contemplaba la creación de un tribunal al que se llevaran "todas las discusiones entabladas entre los dos sexos" (Puleo, 2011, p. 99) y se resolvieran los asuntos que en ese entonces afectaban a las mujeres, como los matrimonios arreglados o la reclusión en un monasterio contra su voluntad, entre otros.

En ese contexto, resuenan con contundencia dos voces femeninas: la de Theroigne de Mericourt -conocida como la Amazona de la Revolución Francesa-, quien en su discurso pronunciado ante la sociedad de los mínimos llamaba a las mujeres francesas a armarse y combatir por la libertad, la cual, tal vez, apreciaban más que los hombres porque "los efectos del despotismo" pesaban más duramente sobre sus cabezas que sobre las de ellos; y la de Olympe de Gouges, quien junto a otras mujeres redactó Los derechos de la mujer y la ciudadana y otros escritos en los cuales abogaba por la igualdad entre los géneros y afirmaba que el hombre

[...] extrańo, ciego, hinchado de ciencias y degenerado, en este siglo de luces y de sagacidad, en la ignorancia más crasa, quiere mandar como un déspota sobre un sexo que recibió todas las facultades intelectuales y pretende gozar de la revolución y reclamar sus derechos a la igualdad (Puleo, 2011, p.155).

Estos reclamos, aunados a la solicitud de un plebiscito nacional para decidir la forma de gobierno que más convenía a Francia y su crítica a Robespierre, la llevaron a la guillotina el 3 de noviembre de 1793, con lo cual se dio inicio durante la llamada época del terror a la persecución de las mujeres que reclamaban su derecho a participar en la vida pública.

Para este grupo de mujeres que participaron activamente en los acontecimientos de la Revolución Francesa, era claro que todas estas situaciones estaban sustentadas en prejuicios: herencia de dogmas de los tiempos bárbaros y siglos de vivir en la ignorancia, en los cuales imperaba la ley de los más fuertes y el sometimiento de los débiles (Puleo, 2011) y que nada tenían que ver con aquella filosofía que ilustraba a la nación. Situaciones todas estas que generaban no solo una condición de pobreza, sino también de subordinación, de menor valía y, por lo tanto, de estatus social que las excluía de todos los espacios de decisión tanto en el mundo privado como en el público.

La otra cara de estos debates, es decir, los argumentos de quienes de manera explícita consideraban que a las mujeres no se les debía otorgar la ciudadanía activa, la expuso fundamentalmente Rousseau, aunque hubo otros como John Locke -a quien se le reconoce como el padre del liberalismo- que coincidía con esta postura. Respecto a esta posición, Rousseau consignó estos argumentos en Emilio o De la educación.

En su lucha por la ciudadanía, las mujeres, finalmente, quedaron incluidas en el nuevo orden político como ciudadanas pasivas, sin capacidad de intervención ni de constituirse en electoras, menos como elegibles. Esta condición de ciudadanía pasiva otorgada a las mujeres ciertamente las excluyó de la vida política y les negó la posibilidad de ser consideradas ciudadanas con plenos derechos, pese a que Diderot (1999) afirmó que ciudadano "es aquel miembro de una sociedad libre de varias familias que comparte los derechos de esta sociedad y se beneficia de esas franquicias" (p. 23). En lo social y cultural, se reafirmaría el ideal de mujer burguesa, hilvanado con argumentos deterministas que interpretaban las diferencias biológicas como expresión de inferioridad en las mujeres y superioridad en los varones.

Autores como Locke y Rousseau, contractualitas y defensores de la idea moderna de igualdad, excluyeron a las mujeres del espacio público al considerar el ámbito privado como el lugar apropiado para las mujeres. Según Rousseau, los hombres se encuentran mejor dotados en inteligencia y valor que las mujeres; una idea que también reiterada por Locke, quien afirmaba que el derecho a decidir únicamente recaía en el hombre por el simple hecho de ser más capaz y más fuerte.

Los argumentos rousseaunianos apuntalaron con mayor fuerza el ideal de la mujer confinada al hogar y sujetada a su esposo y a sus hijos, que ya existía en voces y argumentos de autores como Fray Luis de León, en cuya obra La perfecta casada afirmaba: "Como son los hombres para lo público, así las mujeres para el encerramiento; y como es de los hombres el hablar y el salir a la luz, así dellas el encerrarse y encubrirse" (De León, 2012).

Este autor -como otros de su tiempo- basaba sus argumentos en las diferencias biológicas entre los sexos, los cuales, sumados a los establecidos en el mito fundacional del judaísmo en el libro del Génesis -según el cual Dios saca a Eva de una costilla de Adán-, justificaron la subordinación de las mujeres, lo que implicaba, además de la obediencia, el silenciamiento de su voz. Dos condiciones 
prejuiciosas que imposibilitaron la actuación pública de la mujer. Fray Luis de León consideraba al respecto:

Así como la Naturaleza [...] hizo a las mujeres para que encerradas guardasen la casa, así las obligó a que cerrasen la boca. Y como las desobligó de los negocios y contrataciones de fuera, así las libertó de lo que se consigue a la contratación, que son las muchas pláticas y palabras. Porque el hablar nace del entender [...]; por donde, así como a la mujer buena y honesta la naturaleza no la hizo para el estudio de las ciencias ni para los negocios de dificultades, sino para un solo oficio simple y doméstico, así les limitó el entender, y por consiguiente, les tasó las palabras y las razones [...] Su hermosura es el hablar escaso y limitado (2012, pp. 67-68).

\section{A modo de cierre}

Aunque la Revolución Francesa y el nuevo orden político surgido de su seno derribaron el andamiaje político, administrativo, social y económico del Antiguo Régimen, dejaron intactos los prejuicios culturales respecto a las mujeres. Los argumentos rousseaunianos no difirieron de lo que social y culturalmente se consideraba el deber ser de las mujeres, máxime si esto era "dado por la naturaleza". El liberalismo no otorgó la igualdad a las mujeres. Los argumentos, en la mayoría de casos, se amparaban en las denominadas leyes naturales.

En Emilio o De la educación, Rousseau plasma el tipo de educación que debe recibir un ciudadano para asumir su autonomía, su libertad y su actuación en el espacio público. El último capítulo lo dedica a Sofía, quien encarna el ideal de mujer, la que

[...] por la misma ley de la naturaleza, tanto en lo que a ellas se refiere como en lo que se refiere a sus hijos, están a merced del juicio de los hombres [...] No hay paridad ninguna entre ambos sexos en cuanto a lo que es consecuencia del sexo. El varón solo en ciertos instantes lo es, la hembra es toda su vida hembra, o al menos toda su juventud: todo la llama a su sexo y para desempeñar bien sus funciones necesita de una constitución que a él se refiera (Rousseau, 1975, p. 281).

De esta condición de naturaleza, según Rousseau, se desprendió, para entonces, lo que en cuestión de educación para ellas debió estar vedado:

La investigación de las verdades abstractas y especulativas, de los principios, de los axiomas en las ciencias, todo cuanto tiende a generalizar las ideas no es de la pertenencia de las mujeres, cuyos estudios deben todos relacionarse con la práctica; a ellas corresponde realizar la aplicación de los principios hallados por el hombre, y también hacer las observaciones que conducen al hombre al establecimiento de los principios. [...] en cuanto a las obras de la inteligencia, estas las exceden; ellas no poseen la suficiente justeza y atención para lograr éxito en las ciencias exactas (1975, p. 434).

Sin los conocimientos para las mujeres que aportaban las diferentes ciencias, los que además la llevarían necesariamente al ámbito público, solo les quedaba la opción del ámbito privado, para cuyo desempeño lo que se les debía enseñar y ellas aprender era

[...] las labores de su sexo, incluso aquellas que no son corrientes, como cortar y coser sus vestidos. A estas labores debe agregársele el conocimiento prioritario del gobierno de su casa, como esposa y madre de familia: Sabe de cocina y de servicio de mesa; conoce el precio de los artículos y las cualidades, [...] Formada para ser un día madre de familia ella también, al dirigir la casa paterna, aprende a gobernar la suya (Rousseau, 1975, p. 443).

De igual forma, Rousseau planteaba que todo cuanto había de aprender una mujer debía estar orientado a la satisfacción de las necesidades y deseos de los hombres, pues su deber era complacer y serles útil, amándolos y honrándolos, educándolos en su época de niños y jóvenes; cuidándolos, dándoles consuelo y aconsejándolos. Esto era lo que se debía enseñar a las mujeres desde la temprana edad -concluía este pensador-, para quien la castidad, el honor y la reputación eran los atributos más especiales, por lo que ellas también debían ser fieles y ser consideradas como tales por parte de sus esposos y demás integrantes del núcleo familiar y la sociedad en general (Rousseau, 1975).

Fue este el ideal de mujer que trascendería y se impondría hasta los ańos sesenta y setenta del siglo XX, promovido fundamentalmente por la Iglesia católica-institución de gran influencia sobre las mujeres-que lo amalgamó con el modelo mariano y lo impuso a través de la educación, principalmente por tener un fuerte contenido confesional católico. Educación y fe hicieron la tarea de instaurar este modelo en el comportamiento individual y colectivo no solo de las mujeres, sino también de la sociedad en general.

Este modelo de mujer sería combatido por las luchas del movimiento sufragista y feminista desde mediados del siglo XIX y todo el siglo XX, para lograr que los Estados reconocieran a las mujeres la igualdad de derechos políticos. Los avances empezarían a verse hacia 1893, cuando en Nueva Zelanda fue otorgado a las mujeres el derecho al voto; ejemplo que han seguido hasta nuestros días la mayoría de los 194 países que hoy existen, aunque queda un reducido grupo de países (Arabia Saudita, Emiratos Árabes Unidos, Brunei, Vaticano y el Líbano) en los que las mujeres no pueden votar. 
Cabe decir que a pesar de la obtención del voto y de los avances que en cuestión de derechos han logrado las mujeres, luego de más de 250 años desde aquellos debates enmarcados en la Revolución Francesa aún persiste en los imaginarios culturales de la mayoría de las sociedades representaciones mentales que excluyen a las mujeres de la participación política, ya no porque se considere que esta no tiene capacidad de razonar, sino porque, como en aquella época, se sigue asumiendo que el papel principal de las mujeres es el de madre y este se cumple principalmente en el ámbito privado, así no se la excluya del ámbito público, principalmente en lo concerniente al mercado laboral.

Según el informe sobre brechas de género del Foro Económico Mundial (2013),

"en ninguna parte del mundo hay igualdad de género" y en cuanto a la participación política se indica que "la mayoría de los países incluidos en el informe, se encuentran lejos de conseguir la paridad”. Según la organización Mujer, de las Naciones Unidas, los parlamentarios nacionales (en el mundo) del sexo femenino solo equivalen al $20,9 \%$ a julio de 2014 y son escasas las mujeres en los máximos cargos de gobierno (ONU-Mujer, 2014). En el 2013, apenas había ocho mujeres jefes de Estado y catorce jefes de Gobierno, todo lo cual significa que tanto los Estados y las sociedades deben continuar trabajando para lograr que la promesa de igualdad sea una realidad para mujeres y hombres en todos los ámbitos de la vida y en todas las sociedades, sin que medie otra premisa que la de pertenecer a la humanidad.

\section{Referencias}

Choderlos de Laclos, P. (2010). La educación de las mujeres y otros ensayos. Traducción, introducción y notas de Julio Seoane Pinilla. Madrid: Siglo XXI.

De León, L. (2014). La perfecta casada. Recuperado de http:// goo.gl/ARDn8R

Diderot, D. (1999). Textos políticos. En: M. E. Alonso \& E. C. Vázquez (Eds.), Historia: El mundo contemporáneo. Documentos y testimonios (pp. 15-20). Buenos Aires: Aique.

Foro Económico Mundial. (2013). América Latina cierra la brecha de género. Recuperado de http://goo.gl/nTplwO

Mill, J. S. (1985). Del gobierno representativo. Madrid: Editorial Tecno S.A.

Noria, O. (1999). La teoría de la representación politica del abate Sieyés. La idea de la voluntad constituyente. Caracas: Universidad Católica Andrés Bello.

Organización de las Naciones Unidas-Mujer. (2014). Hechos y cifras: liderazgo y participación politica. Recuperado de http:// goo.gl/n0GVJL

Puleo, A. (2011). La Ilustración olvidada. La polémica de los sexos en el siglo XVIII. Barcelona: Anthropos.

Rousseau, J. J. (1975). Emilio, o De la educación. Barcelona: Editorial Bruguera.

Rousseau, J. J. (2004). Discurso sobre el origen de la desigualdad de los hombres. Madrid: Calpe.

Sieyes, E. (1978). ¿Qué es el tercer estado? Recuperado de https:// goo.gl/rWI470 